\title{
Factors associated with health-related quality of life of military policemen in Salvador, Brazil: cross-sectional study
}

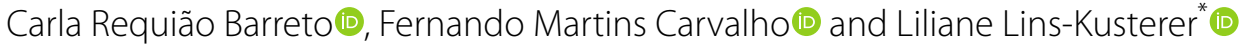

\begin{abstract}
Background: Brazil is a violent society and police officers play a fundamental role in this scenario. Police work is a stressful occupation. Dealing with routine violence, police officers must have high standards of physical and mental health. Patrolling the streets involves several risks and stressful situations that may hamper military policemen's quality of life. The identification of factors associated with health-related quality of life may help in planning and providing adequate care to military policemen. This study aimed to identify factors associated with health-related quality of life of military policemen in Salvador, Brazil.
\end{abstract}

Methods: A cross-sectional design study investigated a random sample of 329 male military police officers, engaged in patrolling the streets of Salvador, Brazil. A structured questionnaire applied to the policemen collected information about age, education, marital status, income, house ownership, car ownership, police rank, working day, alcohol consumption, smoking, frequency of vigorous physical activity, obesity (body mass index $\geq 30.0$ ), and work ability. Healthrelated quality of life was evaluated through the 36-Item Short Form Health Survey Questionnaire (SF-36). Work ability was assessed through the Work Ability Index questionnaire. Poor work ability was defined by a 7-27 points score. Multiple linear regression models were used to measure the impact of police officers characteristics on the variation in the Physical Component and Mental Component Summary scores.

Results: Normalised scores were below $50.0 \%$ for seven out of the eight SF-36 domains and for the two component summaries. The SF-36 Physical Component Summary was significantly $(P<0.05)$ associated with poor work ability, while the Mental Component Summary was associated with poor work ability, excessive alcohol consumption, and younger age (24-34 years). Multivariate analysis estimated that the Physical Component Summary was 7.386 units (\%) lower among policemen with poor work ability compared to those with moderate/good/excellent work ability. The Mental Component Summary was 12.755 units lower among those with poor work ability, 5.354 units lower among those with excessive alcohol consumption, and 5.532 units higher among those with younger age.

Conclusions: The military police officers investigated presented low health-related quality of life, associated with younger age, excessive alcohol consumption, and poor work ability.

Keywords: Police, Quality of life, Work capacity evaluation, Cross-sectional studies

*Correspondence: Ikusterer@gmail.com

Postgraduate Program in Health, Environment, and Work, Federal University of Bahia, Largo do Terreiro de Jesus, S/N Centro Histórico, Salvador, Bahia CEP 40026-010, Brazil

\section{Background}

During the Vietnam War, between 1955 and 1975, 47,406 American soldiers were killed in action or captivity [1]. In Brazil, in 2018 alone, 57,358 intentional violent deaths were recorded, corresponding to 27.5 deaths per 100,000 inhabitants. Eleven out of 100 deaths were caused by 
police officers. Conversely, 343 policemen were killed, $256(75 \%)$ of these deaths occurred outside working hours [2].

As other Latin American countries, Brazil is a violent society and police officers play a fundamental role in this scenario. Police work is a stressful occupation. Dealing with routine violence, police officers must have high standards of physical and mental health, which usually deteriorate over time [3]. Patrolling the streets involves dealing with theft, drug-trafficking, criminal behaviour, long working hours, the possibility of being injured or killed, and other stressful situations that may damage their physical [4] and mental health [5].

Information obtained after identification of factors associated with health-related quality of life may be useful to propose adequate policies and to implement effective care to military policemen. This study aimed to identify factors associated with the health-related quality of life (HRQoL) of military policemen in the city of Salvador, in the state of Bahia, Brazil.

\section{Methods}

A cross-sectional study of factors associated with healthrelated quality of life was carried out in a representative sample of military policemen from Salvador, Bahia, Brazil.

Salvador city had estimated 2.9 million inhabitants in 2016; in 2014, its per capita Domestic Gross Product was R\$ 19.5050,84 (equivalent to US\$ 8386), ranking 26 among the 5565 Brazilian municipalities [6]. In 2010, the Human Development Index of Salvador was high $(\mathrm{HDI}=0.759)$, ranking 383 among Brazilian municipalities [7]. Salvador is a violent city. In 2014, 1309 cases of homicide were reported in Salvador, corresponding to a rate of 48.1 homicides per 100,000 inhabitantes. In 2014, approximately $11 \%$ of the 31,039 military policemen in the State of Bahia worked in Salvador [8].

The accessible population was composed of all the 3500 military police officers from 27 battalions. The study included only males, engaged in visible patrolling in public spaces in the city, and excluded those who were on medical leave, engaged in administrative functions, or in specific situations not related to their core-activity. This study is part of a larger study that evaluated other health aspects in military police officers from Salvador [9].

Between February and April 2014, a trained researcher applied an individual, structured questionnaire to the policemen during their working hours. The policemen were individually interviewed, in a reserved consultation office of the batallion. All randomly selected policemen participated voluntarily in the survey. Information was collected about age (24$34 ; 35-54$ years, using the median as the cut-off point), education (high school; graduate/post graduate), marital status (married; others), income $(2-6 ;>6$ Minimal Wages, equivalent to US\$ 1856 in March, 2014, using the mean salary of a soldier as the cut-off point) house ownership (yes; no), car ownership (yes; no), police rank (officer; soldier), working day $(\leq 8 \mathrm{~h} /$ day; $>8 \mathrm{~h} /$ day), excessive alcohol consumption (yes; no-the latter including none and light), smoking (no/ex-smoker; smoker), vigorous physical activity (up to 2 times/week; 3-7 times/week) and obesity(yes; no), defined as body mass index $\geq 30.0[10]$.

The policeman's own perception of their work ability was measured by the Work Ability Index-WAI [11]. The Work Ability Index questionnaire has been translated [12] and validated for the Brazilian population, with satisfactory construct validity and reliability [13] and test-retest reliability [14]. WAI has seven dimensions: current work ability compared to lifetime best (0-10 points), work ability in relation to demands of the job (2-20 points), number of diseases diagnosed by a physician (1-7 points), estimated work impairment due to diseases (1-6 points), sick leave over the past 12 months (1-5 points), own prognosis of work ability 2 years from now (1-7 points), and mental resources (1-4 points). WAI is calculated through the sum of points over the seven dimensions, varying from 7 to 49 points. The score can be classified according to four work ability categories: poor ( $7-27$ points), moderate ( $28-36$ points), good (37-43 points), and excellent (44-49 points) [15]. For the purposes of this study, poor work ability was codified as Yes (WAI 7-27 points) or No (WAI 28-49 points).

Health-related quality of life was evaluated using the 36-Item Short Form Health Survey questionnaire (SF-36) [16], cross-culturally validated to Brazilian Portuguese [17].

A random sample, proportionally stratified by the 27 battalions, was selected. As recommended by the SF-36 manual [18], Cohen's [19] formula was used to calculate a sample size capable of detecting differences of 5.0 points between the sample mean and the mean of a fixed standard. To estimate the population's standard deviations, the values for males aged 25-34, 35-44, and 44-54 years old were adopted, as demonstrated in Table 10.3 of the SF-36 manual [18]. The value 30.24 , related to the Role Physical domain, for men aged 44-54 years, was used, since this was the largest of the three age groups and the eight SF-36 domains. The estimated minimal sample size was $n=289$, but this was deliberately inflated by $20 \%$, resulting in a desired sample size of $n=347$ policemen. There were no refusals, however 18 individuals returned questionnaires with incomplete answers and were excluded from the study. The final sample size was composed of 329 policemen. 


\section{Data processing and analysis}

Based on answers to the SF-36 questionnaire, eight multi-item scales (physical functioning, role limitations due to physical problems, bodily pain, general health perceptions, vitality, social functioning, role limitations due to emotional problems and mental health) were constructed and subsequently aggregated into two Component Summaries: the Physical Component Summary and the Mental Component Summary. The eight scales were scored using raw data (0-100 algorithms), while the respective normalized scores and the scores for the two summary measures was performed using QualityMetric Health Outcomes ${ }^{\mathrm{TM}}$ Scoring Software 4.0 [20]. The study was licensed by QualityMetric Health Outcomes ${ }^{\mathrm{TM}}$ under number QM025904. The normalization procedure transforms raw scores into a mean of $50 \%$ and a standard deviation of 10, taking the United States of America general population as a reference. This transformation achieves the same mean and standard deviation for all SF-36 scales and summary measures. Because of their comparable variance, normalized scores enable comparisons between the respective domain and the component scales. Higher scores represent better health-related quality of life.

The internal consistency of the SF-36 and WAI domains was evaluated using Cronbach's alpha. Values should exceed 0.70 , but values $\geq 0.60$ are acceptable in exploratory research [21].

Literature discuss whether the WAI questionnaire presents one or two dimensions [22]. In order to access dimensionality, parallel analysis (PA) technique was applied to WAI data, using polychoric correlations and Robust Unweighted Least Squares method for the factor extraction [23].

Bivariate analyses used $t$-tests to compare means from the independent samples. Multivariable linear regression models were used to measure the impact of police officer characteristics on variation in the Physical Component and Mental Component Summary scores. All prediction variables (age, education, marital status, income, house ownership, car ownership, police rank, working day, excessive alcohol consumption, smoking, vigorous physical activity, obesity, and poor work ability) were inserted as a block in each equation, using the default selection method 'Enter'. Cases presenting studentized residual analysis varying around \pm 3.000 standard deviations were identified as outliers. Data were analysed using SPSS version 20.0 (IBM Corp., Armonk, NY, USA).

After explanation of the study objectives, participants signed a free informed consent form. All information related to the participants was confidential. The study was approved by the Ethics Committee in Research on Human Beings of the Medical School of Bahia for opinion number 554,724 .

\section{Results}

Normalised scores were below 50.0 for the eight SF-36 domains and the two component summaries, except for vitality $(51.8 \pm 10.7)$. Scores for general health $(44.6 \pm 7.8)$ and social functioning $(43.9 \pm 11.1)$ were particularly low. The internal reliability indices for each domain, measured by Cronbach's alpha coefficient, varied from 0.624 (General Health) to 0.896 (Physical Functioning) (Table 1).

Parallel analysis suggested only one dimension to represent the model for the WAI data. The reliability of the WAI questionnaire, measured by a Cronbach's alpha $=0.844$, was higher than the recommended threshold value (0.70).

The policemen in the study were predominantly married (61.1\%), presented low levels of education (64.4\%), were soldiers $(92.4 \%)$, owned a car $(70.2 \%)$, and worked $>8 \mathrm{~h} /$ day $(79.6 \%)$. They did not practice vigorous physical activity frequently (47.7\%), and some were obese (14.3\%), smokers (5.8\%), heavy drinkers (7.3\%), and presented poor work ability (10.3\%). Bivariate analyses revealed that the Physical Component Summary was strongly $(P<0.05$ or less) associated with working day $(P=0.023)$, vigorous physical activity $(P=0.045)$, obesity $(P=0.041)$, and poor work ability $(P<0.001)$. The Mental Component Summary was significantly lower among military policemen from age group $24-34$ years $(P=0.005)$, with excessive alcohol consumption $(P=0.002)$ and poor work ability $(P<0.001)$ (Table 2$)$.

Multiple linear regression analyses revealed that the Physical Component Summary was associated with poor work ability $(P<0.001)$. Equation 1 estimates that the mean Physical Component Summary was 7.368 units (\%) lower among those with poor work ability. Equation 2 revealed that the Mental Component Summary was associated with poor work ability $(P<0.001)$, excessive alcohol consumption $(P=0.028)$, and age $(P=0.011)$. Equation 2 estimates that the mean Mental Component Summary

Table 1 SF-36 normalized scores (in \%) and respective Cronbach's alpha coefficients of $\mathbf{3 2 9}$ military policemen

\begin{tabular}{lll}
\hline SF-36 & Mean \pm SD & Cronbach's alpha \\
\hline Physical functioning (PF) & $49.8 \pm 8.6$ & 0.896 \\
Role physical (RP) & $46.0 \pm 10.7$ & 0.815 \\
Bodily pain (BP) & $47.4 \pm 11.3$ & 0.863 \\
General health (GH) & $44.6 \pm 7.8$ & 0.624 \\
Vitality (VT) & $51.8 \pm 10.7$ & 0.866 \\
Social functioning (SF) & $43.9 \pm 11.1$ & 0.743 \\
Role emotional (RE) & $45.4 \pm 12.3$ & 0.828 \\
Mental health (MH) & $47.2 \pm 12.0$ & 0.856 \\
Physical Component Summary (PCS) & $47.9 \pm 8.2$ & - \\
Mental Component Summary (MCS) & $46.4 \pm 11.7$ & - \\
\hline
\end{tabular}


Table 2 Physical (PCS) and Mental (MCS) Component Summaries scores (\%) according to characteristics of military policemen

\begin{tabular}{|c|c|c|c|c|c|c|c|c|}
\hline \multirow[t]{2}{*}{ Characteristic } & \multirow[t]{2}{*}{$\mathbf{N}$} & \multirow[t]{2}{*}{$\%$} & \multicolumn{3}{|l|}{ PCS } & \multicolumn{3}{|l|}{ MCS } \\
\hline & & & Mean & SD & $P^{a}$ & Mean & SD & $P^{a}$ \\
\hline Education & & & & & 0.986 & & & 0.255 \\
\hline High school & 212 & 64.4 & 48.0 & 7.9 & & 46.9 & 11.4 & \\
\hline Graduated/post grad & 117 & 35.6 & 47.9 & 8.8 & & 45.4 & 12.0 & \\
\hline Marital status & & & & & 0.822 & & & 0.722 \\
\hline Married & 201 & 61.1 & 47.8 & 8.2 & & 46.5 & 12.0 & \\
\hline Others & 128 & 38.9 & 48.1 & 8.2 & & 46.1 & 11.2 & \\
\hline Police rank & & & & & 0.250 & & & 0.832 \\
\hline Officer & 25 & 7.6 & 49.7 & 7.2 & & 46.8 & 12.2 & \\
\hline Soldier & 304 & 92.4 & 47.8 & 8.3 & & 46.3 & 11.6 & \\
\hline Income & & & & & 0.090 & & & 0.231 \\
\hline 2-6 min. wages & 298 & 90.6 & 47.7 & 8.3 & & 46.1 & 11.7 & \\
\hline$>6$ min. wages & 31 & 9.4 & 50.3 & 7.2 & & 48.7 & 11.6 & \\
\hline Car ownership & & & & & 0.141 & & & 0.071 \\
\hline Yes & 231 & 70.2 & 48.4 & 7.8 & & 47.1 & 11.3 & \\
\hline No & 98 & 29.8 & 46.8 & 9.1 & & 44.6 & 12.3 & \\
\hline House ownership & & & & & 0.984 & & & 0.465 \\
\hline Yes & 108 & 32.8 & 47.9 & 9.0 & & 47.0 & 11.6 & \\
\hline No & 221 & 67.2 & 47.9 & 7.9 & & 46.0 & 11.7 & \\
\hline Working day & & & & & 0.023 & & & 0.431 \\
\hline$\leq 8 \mathrm{~h} /$ day & 67 & 20.4 & 50.0 & 7.6 & & 47.3 & 10.7 & \\
\hline$>8$ h/day & 262 & 79.6 & 47.4 & 8.3 & & 46.1 & 11.9 & \\
\hline Vigorous physical activity & & & & & 0.045 & & & 0.457 \\
\hline Up to 2 times/week & 157 & 47.7 & 47.0 & 7.9 & & 45.9 & 12.0 & \\
\hline 3-7 times/week & 172 & 52.3 & 48.8 & 8.4 & & 46.8 & 11.4 & \\
\hline Obese & & & & & 0.041 & & & 0.806 \\
\hline No & 282 & 85.7 & 48.4 & 7.8 & & 46.4 & 11.8 & \\
\hline Yes & 47 & 14.3 & 45.2 & 10.1 & & 46.0 & 11.1 & \\
\hline Smoking & & & & & 0.152 & & & 0.632 \\
\hline No/ex-smoker & 310 & 94.2 & 48.1 & 8.2 & & 46.4 & 11.6 & \\
\hline Smoker & 19 & 5.8 & 45.3 & 9.2 & & 45.9 & 12.4 & \\
\hline Age group & & & & & 0.177 & & & 0.005 \\
\hline 24-34 years & 150 & 45.6 & 48.6 & 7.8 & & 44.4 & 12.2 & \\
\hline $35-54$ years & 179 & 54.4 & 47.4 & 8.5 & & 48.0 & 10.9 & \\
\hline Excessive alcohol consumption & & & & & 0.069 & & & 0.002 \\
\hline No & 305 & 92.7 & 48.2 & 8.1 & & 46.9 & 11.5 & \\
\hline Yes & 24 & 7.3 & 45.0 & 9.0 & & 39.4 & 11.3 & \\
\hline Poor work ability & & & & & $<0.001$ & & & $<0.001$ \\
\hline No & 295 & 89.7 & 48.8 & 7.9 & & 47.7 & 10.7 & \\
\hline Yes & 34 & 10.3 & 40.6 & 7.1 & & 34.6 & 13.0 & \\
\hline
\end{tabular}

a Independent samples $t$-test

was 3.532 units $(\%)$ lower $(P<0.006)$ among those aged $35-54$ years, $5.354 \%$ lower $(P<0.028)$ among those with excessive alcohol consumption, and $12.755 \% \%$ lower $(P<0.001)$ among those with poor work ability (Table 3$)$.
Beta (standardized) regression coefficients enable comparisons of the relative effect of each independent variable on the model's dependent variables. Compared to the other twelve variables in the models, poor work ability 
Table 3 Multiple linear regression equations having PCS and MCS (\%) as dependent variable in 329 military policemen

\begin{tabular}{|c|c|c|c|c|c|c|c|c|}
\hline \multirow[t]{2}{*}{ Predictor in the equation (referent) } & \multicolumn{4}{|c|}{ Equation 1 (Dependent $=$ PCS) } & \multicolumn{4}{|c|}{ Equation 2 (Dependent = MCS) } \\
\hline & $b^{a}$ & Std error of $b$ & $P$ & Beta $^{b}$ & $\overline{b^{a}}$ & Std error of $b$ & $P$ & Beta $^{b}$ \\
\hline Education (Grad/postgrad.) & -0.248 & 0.939 & 0.792 & -0.014 & 0.043 & 2.981 & 0.974 & 0.002 \\
\hline Marital status (Married) & -0.583 & 0.934 & 0.533 & -0.035 & 0.078 & 1.303 & 0.952 & 0.003 \\
\hline Police rank (Officer) & 1.189 & 2.294 & 0.605 & 0.038 & 3.044 & 3.181 & 0.339 & 0.069 \\
\hline Income (> 6 Min. wages) & -2.515 & 2.076 & 0.227 & -0.090 & -3.273 & 2.880 & 0.257 & -0.082 \\
\hline Car ownership (Yes) & -0.776 & 0.989 & 0.433 & -0.043 & -1.644 & 1.372 & 0.232 & -0.065 \\
\hline Housing ownership (Yes) & 0.306 & 0.943 & 0.746 & 0.018 & 0.308 & 1.309 & 0.814 & 0.012 \\
\hline Working day ( $\leq 8 \mathrm{~h} /$ day) & -1.139 & 1.136 & 0.317 & -0.056 & 0.190 & 1.576 & 0.904 & 0.007 \\
\hline Vigorous physical activity (3-7 times/week) & -1.327 & 0.881 & 0.133 & -0.081 & -0.574 & 1.222 & 0.639 & -0.025 \\
\hline Obese (Normal/overweight) & -1.532 & 1.299 & 0.239 & -0.065 & 0.840 & 1.802 & 0.641 & 0.025 \\
\hline Smoking (No/ex-smoker) & -1.338 & 1.912 & 0.485 & -0.038 & 0.745 & 2.652 & 0.779 & 0.015 \\
\hline Age group (35-54 years) & -0.932 & 0.928 & 0.316 & -0.057 & 3.532 & 1.288 & 0.006 & 0.151 \\
\hline Excessive alcohol consumption (No) & -1.213 & 1.747 & 0.488 & -0.039 & -5.354 & 2.423 & 0.028 & -0.120 \\
\hline Poor Work Ability (No) & -7.386 & 1.484 & $<0.001$ & -0.275 & -12.755 & 2.058 & $<0.001$ & -0.334 \\
\hline Constant & 52.733 & 2.149 & $<0.001$ & - & 46.467 & 4.205 & $<0.001$ & - \\
\hline
\end{tabular}

${ }^{a}$ Regression coefficient b

b Standardized coefficient Beta

presented the highest betas in both Equation $1(-0.275)$ and Equation 2 (-0.334) (Table 3).

Residual analysis revealed one outlier in Equation 1 (with PCS as the dependent variable), and two outliers in Equation 2 (with MCS as the dependent variable). Excluding these outliers did not substantially change the results in either equation. Collinearity among the predictors did not provide important limitations to the analyses. Tolerance collinearity statistics $\left(1-R^{2}\right)$ were always high for both equations, ranging from 0.502 to 0.957 . Tolerance statistics close to zero indicates that a variable is almost a linear combination of the other predictors in the model. Adjusted $\mathrm{R}^{2}$ was 0.093 in Equation 1 and 0.135 in Equation 2. The Durbin-Watson statistics fell within the acceptable range (1.5-2.5) in Equation 1 (1.972) and in Equation 2 (1.925) (Table 3).

No interaction among variables presented in Table 3 was found, using first-order interaction terms in multiple linear regression analyses. Small numbers in some strata prevented from drawing conclusions about interactions among the predictors investigated.

\section{Discussion and conclusion}

General health and social functioning scores were particularly low for policemen in Salvador. All eight SF-36 scales contributed, with varying weights, to the Physical Component and Mental Component Summary scores. However, physical functioning, role physical, and bodily pain usually contributed more significantly to the Physical Component Summary, whereas social functioning, role emotional, and mental health contributed more significantly to the Mental Component Summary. The vitality, general health, and social functioning scales provided noteworthy contributions to both Physical and Mental Component Summary scores [24].

Reliability was high $(>0.80)$ for most of the SF-36 domains (PF, RP, BP, VT, RE and $\mathrm{MH}$ ); good (0.743) for the SF domain, and acceptable (0.642) for the GH domain.

The Physical $(P<0.001)$ and Mental $(P<0.001)$ Component Summaries of the health-related quality of life of the study population presented strong associations with poor work ability. The Work Ability Index is a complex construct that represents interaction between the individual's resources and their physical, mental and social work demands, the work environment, organizational culture and management. The WAI may be affected by various aspects of a worker's health-related quality of life [15]. Analogously, the SF-36 physical and mental component summaries are also complex constructs that involve a range of aspects related to work ability. Significant relationships were reported between WAI score and all SF-36 dimensions [25, 26].

Compared to the other twelve variables in the models, poor work ability presented the best predictors of the physical and mental component summaries, by some distance. A value 7.386 units (\%) lower was estimated for mean PCS among policemen with poor work ability, compared with policemen with moderate/good/ excellent work ability. For mean MCS, the estimated value was $12.755 \%$ lower among policemen with poor work ability. 
Minimal Clinically Important Difference (MCID) can be defined as the smallest difference in score in the domain of interest which is perceived to be beneficial or harmful, and that would imply in a change in patient's management. Ideally, the MCID should be ascertained to each particular study population [27]. The MCID for group-level is necessarily smaller than for individual patient-level, because of greater measurement error inherent to patient's quality of life scores [28]. To the best of our knowledge, the MCID for the SF-36 Component Summaries (PCS and MCS) have not yet been determined for general or occupational populations, like military policemen.

It is unacceptable for $10.3 \%$ of these military policemen to present poor work ability. Policemen should be physically fit in order to undertake patrols. Difficulty in patrolling the street may be harder to policemen with poor work ability, since they also present lower mental health component of their health-related quality of life.

Policemen who were heavy drinkers presented MCS scores 5.354 lower than those who did not drink alcohol or were light drinkers. The inherently stressful work in the police service may be an important contributor to alcohol use. Excessive alcohol consumption is a frequent problem among a number of occupational groups in the USA, such as miners (17.5\%) and construction workers (16.5\%), aged between 18 and 64 [29]. In a large survey among male police officers from California and New York City, $7.8 \%$ met criteria that indicated probable lifetime alcohol abuse or dependence [30]. This figure is similar to that found for the self-reported excessive alcohol consumption in our study: $7.3 \%$.

Multiple regression analysis revealed a positive, statistically significant $(b=0.237 ; P=0.006)$ association between age and the mental component of health-related quality of life (MCS). This association probably reflects a healthy worker survivor effect [31]. Stressful working conditions can affect policemen's mental health status over time, leading them to choose to leave the workforce, while those presenting optimal physical and mental health tend to remain in the job.

Some limitations of this study need to be addressed. Its cross-sectional design precludes the possibility of establishing causality among our key variables, mainly because of a lack of knowledge about their temporal sequence. Bi-directional cause-effect relationships between HRQoL component summaries (PCS and MCS) and poor work ability cannot be ruled out. Low values of adjusted $R^{2}$ (0.093 for PCS and 0.135 for MCS) can be due to: (1) relevant predictors were not included in the model; and/or (2) a great proportion of the relationship among the outcomes and the predictor variables investigated was not linear.
Despite these limitations, this pioneering study was the first to evaluate the HRQoL of military policemen in a representative sample from a large city in Brazil. The physical and mental components of HRQoL were strongly associated with poor work ability. The mental component of HRQoL was lower among heavy drinkers and those who were younger. Given the key role military policemen play in community safety, these results are worrisome and deserve the attention of military police corporate managers in order to take preventive measures to protect these workers' health. Indeed, the results of this study provided valuable information to the military corporation health department to plan and establish its first Medical Control Program [32].

In conclusion, military police officers from Salvador city presented low health-related quality of life, associated with excessive alcohol consumption and poor work ability, which may hamper their professional activities. The association between younger age and lower mental component of their health-related quality of life (MCS) is probably due to a healthy worker survivor effect. These findings were important in planning the activities of a health care program for this particularly vulnerable occupational group.

\section{Abbreviations}

SF-36: 36-Item Short Form Health Survey Questionnaire; PF: Physical functioning; RP: Role physical; BP: Bodily pain; GH: General health;VT:Vitaliy; SF: Social functioning; RE: Role emotional; MH: Mental health; PCS: Physical Component Summary; MCS: Mental Component Summary; sd: Standard deviation; WAl: Work Ability Index; MCID: Minimal Clinically Important Difference.

\section{Acknowledgements}

The authors would like to thank to all military policemen who participated in this study.

\section{Authors' contributions}

Carla Barreto and Liliane Lins-Kusterer have worked in the conception of the study. Carla Barreto worked in data collection and wrote the first draft. Carla Barreto, Fernando Carvalho, and Liliane Lins-Kusterer have worked on the design of the study, data analysis and interpretation, wrote and critically reviewed successive drafts of the manuscript and approved its last version for publication.

\section{Funding}

Brazilian National Council for Scientific and Technological Development (CNPq). A researcher fellowship grant number 304691/2018-6 on behalf of Fernando M. Carvalho.

\section{Availability of supporting data}

The data supporting the findings of this study are available from Liliane LinsKusterer but restrictions apply to the availabilityof these data, which were used under license for the current study, and so are not publicly available. Data are however available from the authors upon reasonable request and with permission of Liliane Lins-Kusterer.

\section{Ethical approval and consent to participate}

The study was approved by the Ethics Committee in Research on Human Beings of the Medical School of Bahia for opinion number 554,724. All policemen participated voluntarily in the survey and signed a free informed consent form. 


\section{Consent for publication}

Not applicable.

\section{Competing interests}

The authors declare that they have no competing interests.

Received: 23 September 2020 Accepted: 23 December 2020 Published online: 18 January 2021

\section{References}

1. Military Factory. Vietnam War Casualties (1955-1975). 2020. [Internet] Military Factory. [cited 2020 Jan 30]. https://www.militaryfactory.com/vietn am/casualties.asp.

2. Fórum Brasileiro de Segurança Pública. Anuário Brasileiro de Segurança Pública 2019. São Paulo: Fórum Brasileiro de Segurança Pública; 2019. http://www.forumseguranca.org.br/wp-content/uploads/2019/10/Anuar io-2019-FINAL_21.10.19.pdf Acessed 17 Jan 2020 (Portuguese).

3. Silva FC, Hernandez SSS, Arancibia BAV, Castro TLS, Gutierres-Filho PJB, Silva R. Health-related quality of life and related factors of military police officers. Health Qual Life Outcomes. 2014;12:60. https://doi. org/10.1186/1477-7525-12-60.

4. Sörensen L, Smilander J, Louhervaara V, Korhonern O, Oja P. Physical activity, fitness and body composition of Finnish police officers: a 15-year follow-up stydy. Occup Med. 2000;5:3-10. https://doi.org/10.1093/occme $\mathrm{d} / 50.1 .3$.

5. Chen HC, Chou FH, Chen MC, Su SF, Wang SY, Feng WW, et al. A survey of quality of life and depression for police officers in Kaohsiung, Taiwan. Qual Life Res. 2006;15:925-32. https://doi.org/10.1007/s1113 6-005-4829-9.

6. Salvador. Plano Municipal de Saúde do Salvador 2018-2021. Salvador: Secretaria Municipal de Saúde. 2018. 231 p. http://www.saude.salvador. ba.gov.br/secretaria/wp-content/uploads/sites/2/2018/12/Plano-Munic ipal-de-Sa\%C3\%BAde-2018-2021-VOLUME-I_aprovado-pelo-CMS-21.11. pdf. Accessed 1 Oct 2020 (Portuguese)

7. PNUD. Programa das Nações Unidas para o Desenvolvimento. Ranking IDH-M Municípios 2010. PNUD Brasil. 2020. https://www.br.undp.org/ content/brazil/pt/home/idh0/rankings/idhm-municipios-2010.html Accessed 1 Oct 2020 (Portuguese).

8. Forum Brasileiro de Segurança Pública. Anuário Brasileiro de Segurança Pública 2015. São Paulo: Forum Brasileiro de Segurança Pública. Ano 9. 2015. p. 47. www.forumseguranca.org.br/produtos/anuario-brasileiro -deseguranca-publica. Accessed 1 Oct 2020.

9. Barreto CR, Lins-Kusterer L, Carvalho FM. Work ability of military police officers. Rev Saude Publica. 2019:53:79.

10. World Health Organization. Obesity: preventing and managing the global epidemic. Report of a WHO Consultation. Geneva: WHO; WHO Technical Report Series, 894. 2000. http://www.who.int/nutrition/publications/ obesity/WHO TRS 894/en/.

11. IImarinen J. The Work Ability Index. Occup Med. 2007;57:160. https://doi org/10.1093/occmed/kqm008.

12. Tuomi K, Ilmarinen J, Jahkola A, Katajarinne L, Tulkki A. Índice de capacidade para o trabalho. São Carlos: EdUFSCar. 2005 (Portuguese)

13. Martinez MC, Latorre MRDO, Fischer FM. Validity and reliability of the Brazilian version of the Work Ability Index questionnaire. Rev Saude Publica. 2009:43(3):525-32. https://doi.org/10.1590/50034-89102009005000017.

14. Renosto A, Biz P, Pattussi HEA, MP, . Confiabilidade teste-reteste do Índice de Capacidade para o Trabalho em trabalhadores metalúrgicos do Sul do Brasil. Rev Bras Epidemiol. 2009;12(2):217-25. https://doi.org/10.1590/ S1415-790X2009000200011 ((Portuguese)).

15. Gould R, Ilmarinen J, Järvisalo J, Koskinen S, editors. Dimensions of work ability. Results of the health 2000 survey. Vaasa: Finnish Centre for
Pensions. 2008. https://www.researchgate.net/publication/228485936_ Dimensions_of_Work_Ability Accessed 17 Jan 2020.

16. Optum. SF health Surveys. Optum. 2020 [Internet]. Optum [cited 2020 Jan 30]. https://www.optum.com/solutions/life-sciences/answer-resea rch/patient-insights/sf-health-surveys.html.

17. Ciconelli RM. Tradução para o português e validação do questionário genérico de avaliação de qualidade de vida "Medical Outcomes Study 36-Item Short-Form Health Survey (SF-36)". São Paulo, 1997. Doctoral thesis. São Paulo: Universidade Federal de São Paulo. São Paulo. 1997. 148 p. http://repositorio.unifesp.br/handle/11600/15360 (Portuguese).

18. Ware JE Jr, Snow KK, Kosinski M, Gandek B. SF-36 Health Survey. Manual and interpretation guide. (Table 7.8, page 7:12). Boston: Nimrod Press; 1993.

19. Cohen J. Statistical power for the behavioral sciences. Hillsdale: Lawrence Earlbaum Associates; 1988.

20. Saris-Baglama RN, Dewey CJ, Chisholm GB, Plumb E, King J, Rasicot P, et al. QualityMetric Health Outcomes ${ }^{T M}$ Scoring Software 40. Lincoln: QualityMetric Incorporated; 2010.

21. Hair JF, Black WC, Babin BJ, Anderson RE. Multivariate data analysis. 7th ed Harlow: Pearson Education, Inc:; 2014

22. Radkiewicz P, Widerszal-Bazyl M. Psychometric properties of Work Ability Index in the light of comparative survey study. Int Congr Ser. 2005;1280:304-9. https://doi.org/10.1016/j.ics.2005.02.089.

23. Timmerman ME, Lorenzo-Seva U. Dimensionality assessment of ordered polytomous items with parallel analysis. Psychol Methods. 2011;16:209_ 20. https://doi.org/10.1037/a0023353.

24. Ware JE Jr. SF-36 health survey update. Spine. 2000;25(24):3130-9. https ://doi.org/10.1097/00007632-200012150-00008.

25. Abdolalizadeh M, Arastoo AA, Ghsemzadeh R, Montazeri A, Ahmad K, Azizi A. The psychometric properties of an Iranian translation of the Work Ability Index (WAI) questionnaire. J Occup Rehabil. 2012;22(3):401-8. https://doi.org/10.1007/s10926-012-9355-3.

26. Martinez MC, Latorre MRDO. Health and work ability among office workers. Rev Saude Publica. 2006;40(5):851-8. https://doi.org/10.1590/S0034 $-89102006000600015$.

27. King MT. A point of minimal important difference (MID): a critique of terminology and methods. Expert Rev Pharmacoecon Outcomes Res. 2011:11:171-84. https://doi.org/10.1586/erp.11.9.

28. Yost KJ, Eton DT. Combining distribution- and anchor-based approaches to determine minimally important differences: the FACIT experience. Eval Health Prof. 2005;28:172-91. https://doi.org/10.1177/0163278705275340.

29. Bush DM, Lipari RN. The CBHSO report: substance use and substance use disorder, by industry. Rockville, MD: Center for Behavioral Health Statistics and Quality. 2015. https://www.samhsa.gov/data/sites/default/files/repor t_1959/ShortReport-1959.pdf.

30. Ballenger JF, Best SR, Metzler TJ, Wasserman DA, Mohr DC, Liberman A, et al. Patterns and predictors of alcohol use in male and female urban police officers. Am J Addict. 2011;20(1):21-9. https://doi.org/10.111 1/j.1521-0391.2010.00092.x

31. Chowdhury R, Shah D, Payal AR. Healthy worker effect phenomenon: revisited with emphasis on statistical methods - a review. Indian J Occup Environ Med. 2017;21(1):2-8. https://doi.org/10.4103/ijoem.IJOEM_53_16.

32. Bahia. Polícia Militar da Bahia. Subcomando Geral. Portaria 047 de 18 de junho de 2014. Institui o Programa de Controle Médico - PCM na PMBA, e dá outras providências. Salvador: PMBA. 22 p (Portuguese).

\section{Publisher's Note}

Springer Nature remains neutral with regard to jurisdictional claims in published maps and institutional affiliations. 